\title{
Exploring the prevention of Fetal Alcohol Spectrum Disorder in the Northwest Territories of Canada: Brightening our home fires
}

\author{
Dorothy Badry ${ }^{1,3}$ and Aileen Wight Felske ${ }^{2,3}$ \\ ${ }^{1}$ Faculty of Social Work, University of Calgary, Calgary, AB, Canada \\ ${ }^{2}$ Mount Royal University, Calgary, AB, Canada \\ ${ }^{3}$ Members of the Canada FASD Research Network Action Team on Women’s Social Determinants of Health
}

\begin{abstract}
Aims: The prevention of Fetal Alcohol Spectrum Disorder (FASD) in a Northern context from a woman's health perspective was explored in the qualitative research study, Brightening Our Home Fires (BOHF). It is recognized that research on the prevention of FASD is a sensitive topic due to stigma associated with alcohol use during pregnancy. Women's health and FASD prevention were identified as the focus of the research, as they are deeply intertwined topics.
\end{abstract}

Design: The BOHF project was designed as a participation action research project that utilized Photovoice as a primary methodology to approach the topic of FASD prevention in the Northwest Territories (NT) from a women's health lens.

Setting: This research took place in Yellowknife, NT. Participants included both Dene and Inuit women.

Participants: Eight women living in a homeless centre in Yellowknife, Northwest Territories.

Measures: This was a qualitative research study that utilized Participatory Action Research (PAR) to explore women's health in the North. Photovoice was the primary methodology. The analysis of this research focused on both image and text, and a depth analysis of text led to theme identification.

Findings: Findings included the importance, to women participants, of housing, access to treatment resources for alcohol, and engagement with health-related resources, and the challenges they experience that are related to their histories of trauma.

Conclusions: Engagement with women in the NT on FASD prevention was important in broadly identifying the linkages between trauma and alcohol use while respecting context and stigma around alcohol use and pregnancy.

The Brightening Our Home Fires (BOHF) research project was initiated by members of the Canada Fetal Alcohol Spectrum Disorder (FASD) Research Network Action Team (NAT) on Social Determinants of Women's Health. The NAT has a broad focus on FASD prevention from a women's health perspective. The BOHF research project was conceptualized and approached from a traumainformed perspective, using a philosophical and practical framework that considered women's voices as central to the development of knowledge on the complex phenomenon of FASD prevention. This research project grew from a concern identified by two members from the Northwest Territories (NT) who participate in the NAT and who had expressed the need for research on FASD prevention in a Northern context. Exploring the prevention of FASD is important work in the northern parts of Canada, as little is known about intervention and prevention. A proposal to the First Nations Inuit Health Branch of Canada was approved for funding, and research ethics approval was received from the Conjoint Faculties Research Ethics Board of the University of Calgary. A research license that involves a consultation process with participating communities is required for all research in the Northwest Territories; a license for this project was received from the Aurora Research Institute in 2011. The project was completed in 2012. The BOHF Project took place in four communities in the Northwest Territories: Behchokö, Ulukhaktok, Yellowknife and Lutsel K'e. This article focuses on the community of Yellowknife, NT, and the experience of homeless women in this major urban center.

A literature search was undertaken using the Summon Service, a research tool that provides access to over 50,000 journals and periodicals, from over 6,000 publishers. Using the key terms Fetal Alcohol Spectrum Disorder, FASD, women and Northwest Territories, the search yielded nine

Correspondence: Dr. Dorothy Badry, Faculty of Social Work, University of Calgary, 2500 University Drive NW, Calgary AB, Canada T2N 1N4. E-mail: badry@ucalgary.ca

Financial support: The First Nations Inuit and Health Branch provided funding for the BOHF project.

Declaration of interest: The authors declare no conflict of interest.

Keywords: Fetal Alcohol Spectrum Disorder, women’s health, prevention, Northwest Territories, homelessness 
journal articles; however, only four appeared to be somewhat relevant to this work. Although the body of published research articles to draw from for this topic is extremely limited, a strong pool of grey literature is emerging within Canada through organizations such as the Canada FASD Research Network, which has included all the Northwest Territories (Northwest Territories, Yukon and Nunavat) since its inception.

The phenomenon of FASD is an international issue that affects women by positioning them as primarily responsible for this birth outcome. Salmon and Clarren (2011) identify the "need for ways of thinking about FASD prevention that extend beyond an individualized 'alcohol awareness' approach to acknowledge the conditions in which women negotiate and experience the complexities of substance use, pregnancy and mothering” (p. 27). Moffitt (2012) researched the topic of pregnancy in a Dene community in the NT, using Photovoice to explore pregnant women's experiences. Briggs and Pepperell (2009) identify pregnancy as an area where health problems are borne solely by women. They state that “women aren't intentionally abusing their unborn child; they are struggling with a complex and baffling addiction that has biological, psychological and sociological foundations" (p. 54). Further, stigmatization of women who are engaged in substance abuse while pregnant remains a barrier to seeking help. Addressing FASD prevention in the broader context of women's health is essential.

FASD prevention is not a common topic for research in a Northern context. Our primary research question was, "What does health and healing look like for you, in your community?" We settled on this question because of the stigma associated with FASD; we had concerns that directly addressing the issue would be perceived as too threatening by women who have substance abuse issues. Listening to Northern women's perspectives on health provides a basis for the development of an approach to FASD prevention. Experiences that all the women participants in Yellowknife had in common were homelessness and struggles with alcoholism. The participants ranged in age from 26 to 62, and all had children - some grown up, some in government care and some with relatives. It was the perspectives of these women that sowed the seeds for this article.

\section{Objectives of the Research}

- To identify voices of women in their home communities through Photovoice work that promotes an understanding of health and healing, with a goal of prevention of FASD.

- To understand the factors that Northern women see as contributing to their health and healing in their own community.

- To engage in a participatory, community-development approach to understanding potential intervention models that would focus on the relationship between trauma, women's health, and FASD prevention that is specific to Northern communities.
The BOHF project had many facets and was really an exploratory project in understanding ways to approach FASD prevention in a Northern context. While the objectives were clearly related to issues of health, it was also important for this research to provide a linkage to existing literature, if possible. In developing this project and grounding the research, a brief review of the literature was undertaken and is reviewed below.

It is important to raise the issue of FASD prevention in a health context in the North. While the general concern of alcohol misuse as a health issue underlies the problem of FASD, it cannot be addressed without examination of the full context of a woman's life history. If we had just asked about FASD, we might have seriously limited participation in this project. Focusing the question on health and healing instead of FASD was perceived by the women as less threatening, in our experience, even when we were providing information and obtaining informed consents that explicitly mentioned FASD prevention. One woman wisely told us that she thought perhaps using the term FASD was a bit of a barrier, for some participants, to talking about health and alcohol problems. A recent article posted on the Girls, Women, Alcohol, \& Pregnancy website raised the issue of cultural safety, and the need to consider FASD prevention in the context of Canadian history and the legacy of colonization (Lavallee \& Poole, 2009). Hunting and Browne (2012) challenge the gendered approach to FASD prevention and policy, and recommend examination of the rooted structural issues of history, racism, social and economic frameworks that create disadvantages for Aboriginal women in Canada. Challenging discourse that suggests FASD is an Aboriginal issue, and that blames mothers and holds them, as individuals, responsible for maternal health and birth outcomes, is a critical point made by multiple authors (Badry, 2012; Hunting \& Browne, 2012; Poole, 2007; Poole \& Greaves, 2007; Rutman, Callahan, Lundquist, Jackson \& Field, 2000).

\section{Method}

The BOHF project utilized Photovoice, a participatory action research (PAR) approach. Salmon, Browne, and Pederson (2010) suggest that participatory research offers a relevant framework to involve women in research about their lives, and a way to identify and develop "principles that explicate why meaningful, engaged and multidirectional collaboration is essential when conducting studies 'on the margins'” (p. 342). One of the hallmarks of Photovoice as a qualitative research methodology is that participants are positioned as co-investigators of the phenomenon of study - in this case, co-investigators in an exploratory FASD prevention study in the Northwest Territories.

We asked women the primary research question, "What does health and healing look like for you in your community?" This question was considered to be an important entry point into any discussion on FASD prevention, because it focuses on health. The question 
provided women with an opportunity to consider health and healing from their own perspectives, while being informed that FASD prevention was an underlying construct for this research.

An information session about the project was offered to women living in a center near downtown Yellowknife, NT. Yellowknife was included because women from remote Northern communities often migrate to this urban location for reasons such as domestic violence, substance abuse treatment, financial need, homelessness, employment opportunities, and a need for a stronger social resource network. Women who chose to be part of the project met with research team members to discuss their participation and to sign informed consents. The women were excited about the digital cameras and Photovoice training; they shared their excitement with others who also became interested, and the number of participants grew to eight. All eight participants lived in the center.

The Photovoice training was a great way to connect and engage with participants. Once this initial phase was complete, the women went out and took photographs, then met with a team member to download images to the project computer. Each woman then worked individually with a team member to decide which photos to include, and to develop captions for each photo. Current literature on Photovoice outlines a methodological approach that generally involves working in groups, with collaborative discussions about photos and captions that represent a particular group or community (Doyle \& Timonen, 2010; Palibroda, Krieg, Murdock, \& Havelock, 2009; WoodleyBaker, 2009). However, we chose to work with the women individually, because this worked best for them and was their stated preference in this setting. Working in groups with Photovoice is effective when there is a stable environment where participants are readily available for group meetings. In our project, we knew that our participants were often transient; as well, it was clear that reviewing photographs and creating captions was a deeply personal process. As our participants were homeless women living in a center, it was necessary to pay attention to that context; there were issues of trust and a need for confidentiality, and we recognized that processing the information required time, attention and one-to-one conversations. The restrictions of the environment included limited space and the busyness of the place people were coming and going, accessing services such as childcare and a clothing bank. Nonetheless, we were able to find a space in which to work and engage with the women. Once the work with each woman was completed, a PowerPoint presentation was created that included the images and text she had selected for inclusion, and she received a $\mathrm{CD}$ of the presentation as well as a printout.

The process of adjusting the methodology of Photovoice to the conditions in the NT unfolded naturally, as it was driven by our engagement with the women in their communities and was based on their needs. Another factor was time; when we were in a community, the primary focus was on working directly and intensively with the women, and gathering photos, captions, thoughts and ideas as each woman returned with her material.

\section{Results}

When Photovoice is used as a primary methodology, issues related to data analysis become bound up with image and text. For the analysis, all the images and text were compiled into PowerPoint presentations created for each participant. In reviewing these slides, an initial process of coding and theming was developed, as common threads of text became visible across participants. Further, all text was uploaded into Atlas $\mathrm{Ti}$ and subsequently coded and analyzed. The process of generating themes came about through repeated coding and analysis of text in Atlas Ti an extensive process. Overarching codes began to emerge that informed the development of themes. Select quotes that would support the themes were also highlighted through this process.

The analysis examined aspects of meaningfulness in the lives of women participants, as illuminated through their photos and text. Some questions emerged through this process: What is meaningful in this woman's life experiences? What is important? How do these images and this text reflect a woman's lived experience? Societal discourse often defines the lives of others, often without asking them about their experiences. The role of the researcher is to get as close as possible to the primary accounts of events and experiences, as shared by those experiencing the phenomenon of study. Through engaging with women who had come from many different places in the Northwest Territories, and who found themselves homeless and living in the urban center of Yellowknife, we learned that the landscape is indeed challenging. The analysis of text and image provides a place to begin to develop a deeper understanding of women's lived experience.

This project facilitated opening a door to have a bit of an inside look at the experiences and lives of women who are concerned about their health, family and culture. It is not possible to include the spectrum of images generated within this project. However, the images and text that were reviewed and analyzed were clearly reflective of different constructs related to the participants' lived experience. These constructs are both physical and metaphorical/symbolic of aspects of a woman's life. These were some key constructs and themes that emerged:

- Place and Environment - Women in Yellowknife identified place as a challenge. Living in a center with many women was challenging, particularly for women over 40. Women from Inuit communities particularly identified that they missed their homes and "country food." Women in Yellowknife were challenged by life on the streets. Three women participants, on different visits, had visible black eyes that they explained had been caused by assaults by other women. Issues such as jealousy and being put down were raised in discussions with the participants. While connection with the land was important, the urban environment 
held its challenges, identified as safety and security. Sleeping on mats was a struggle on a daily basis, often for years; this was a concern highlighted by the women, as personal rooms are generally unavailable in the center.

- Family - All the women in Yellowknife maintained connections with relatives, and many viewed their friends who were also homeless as "sisters." Two women shared that their children were in foster care but they were able to maintain visitation.

- Tradition - Linkages to culture and family were identified as important. Women were excited when "country food" was donated to the center and spoke highly of the value of receiving such donations.

- Spirituality - It was important for women to have a spiritual life and hold a belief in a higher power, particularly in the face of addictions.
Health - Women in Yellowknife valued having a nurse visit the center, and felt that they ate more regularly in the center and paid better attention to nutrition; access to addiction treatment was also important, when a woman was ready for this. Women generally expressed that living in a center did not make them feel healthy, and they expressed the need for more support in healing past traumatic experiences.

These should be regarded as important themes affecting women's lives in the North.

Participants were very interested in the experience of taking photographs, and in talking about health and healing, as this is an integral part of daily life even while struggling with homelessness. They expressed a sense of pride in taking and sharing photographs. The following examples are representative of the work of three women participants, and were produced during the project.

\section{Figure 1}

Homeless sisters working together on a project. This is the first thing I'm starting on just trying to learn one day at a time, working on those things like learning computers instead of being out there. Doing simple things to keep my mind away from other things I have done in my life. If I just stay forward hopefully there is something out there that will keep my mind off drinking and find a simple thing to keep me doing other things I want to do in my life. May the good spirit always be with us.

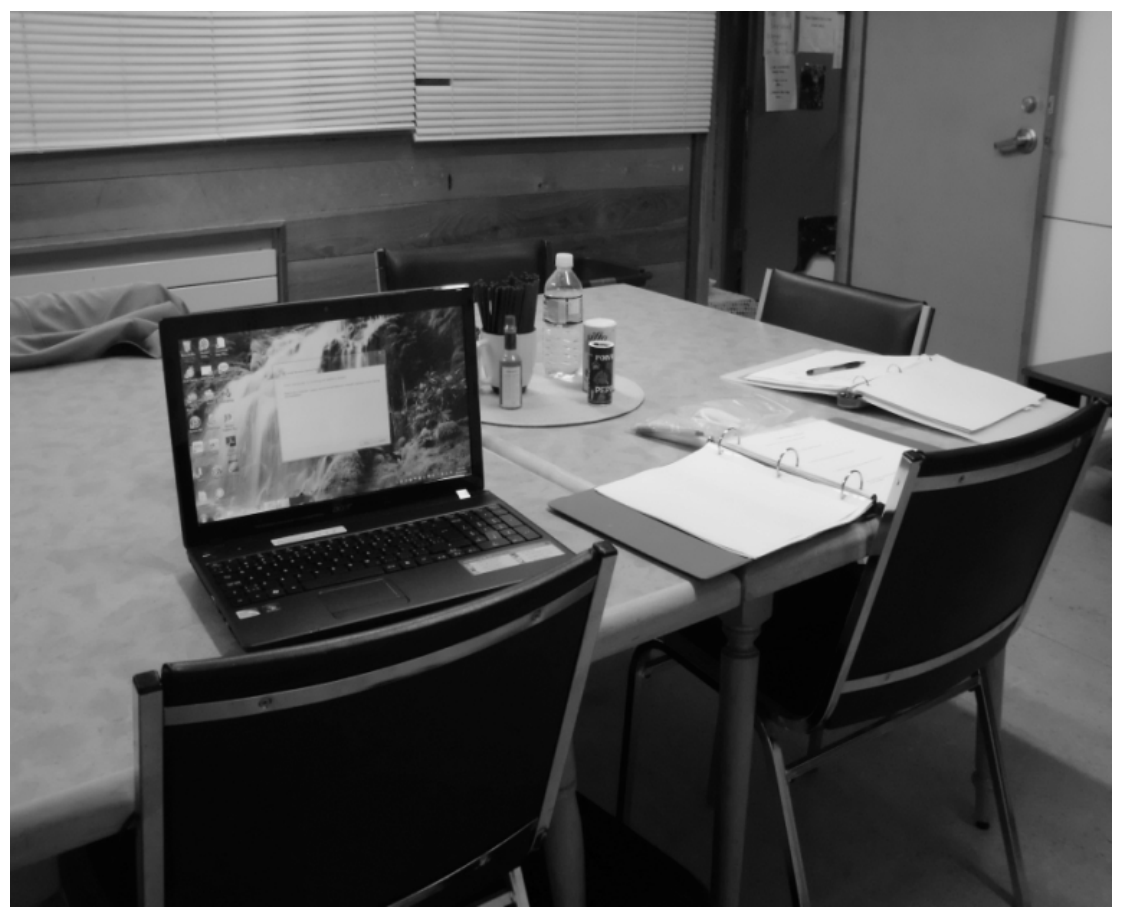




\section{Figure 2}

The Tree. The tree clears the air and it's healthy. It's part of nature, part of the world. We need the tree. It makes me happy because it looks nice there. It makes it nice for the city. It makes me feel sad for the tree being in the cold weather. It is challenging to be in the cold. I've been out in the cold and it's cold, very cold.

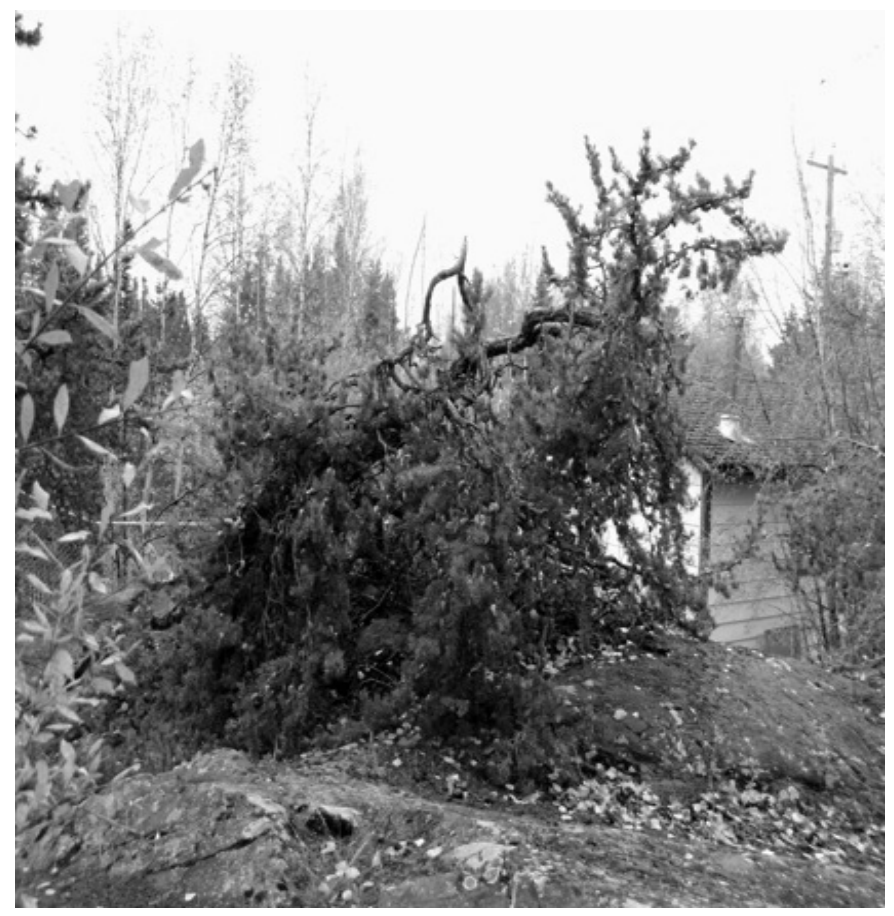

\section{Figure 3}

The Rocks. If you want to rest, if you are tired you can rest on the rock. I rested on the rock. It's uncomfortable, and it's comfortable.

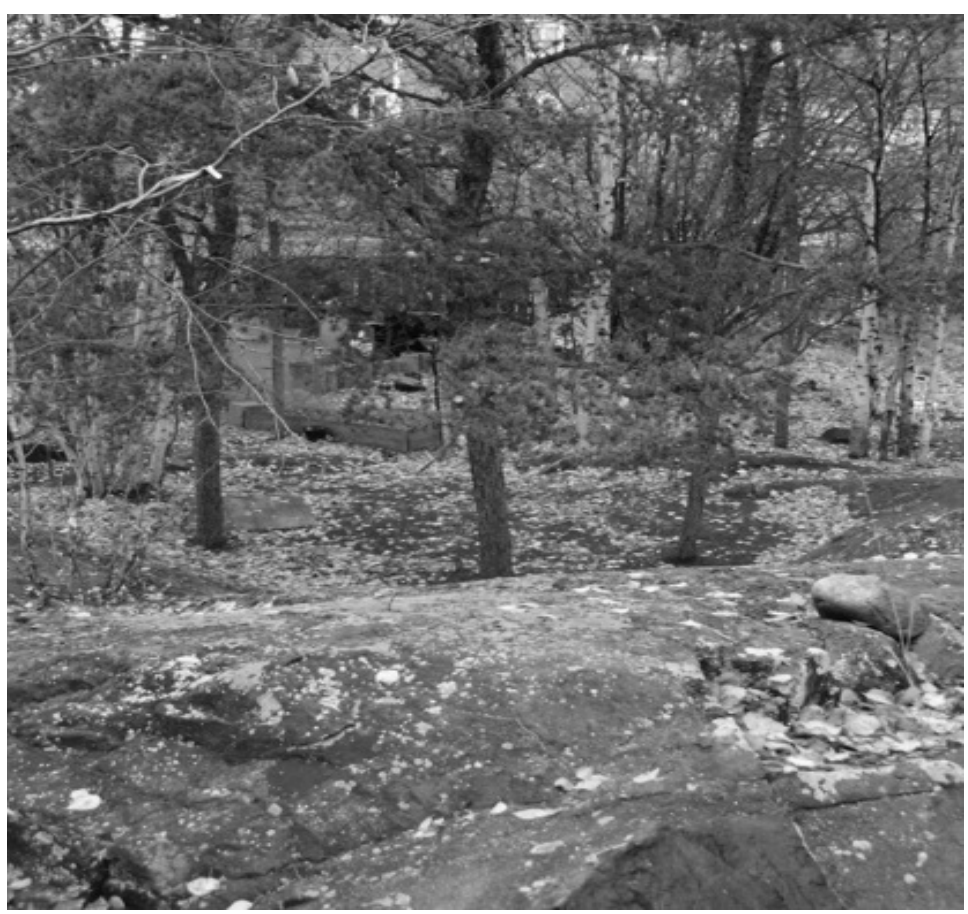




\section{Figure 4}

My Friend Rita [on the importance of supportive relationships]. It means a lot that her and me can still hold hands - she has strong features and so do I - makes me feel good that she is there for me.

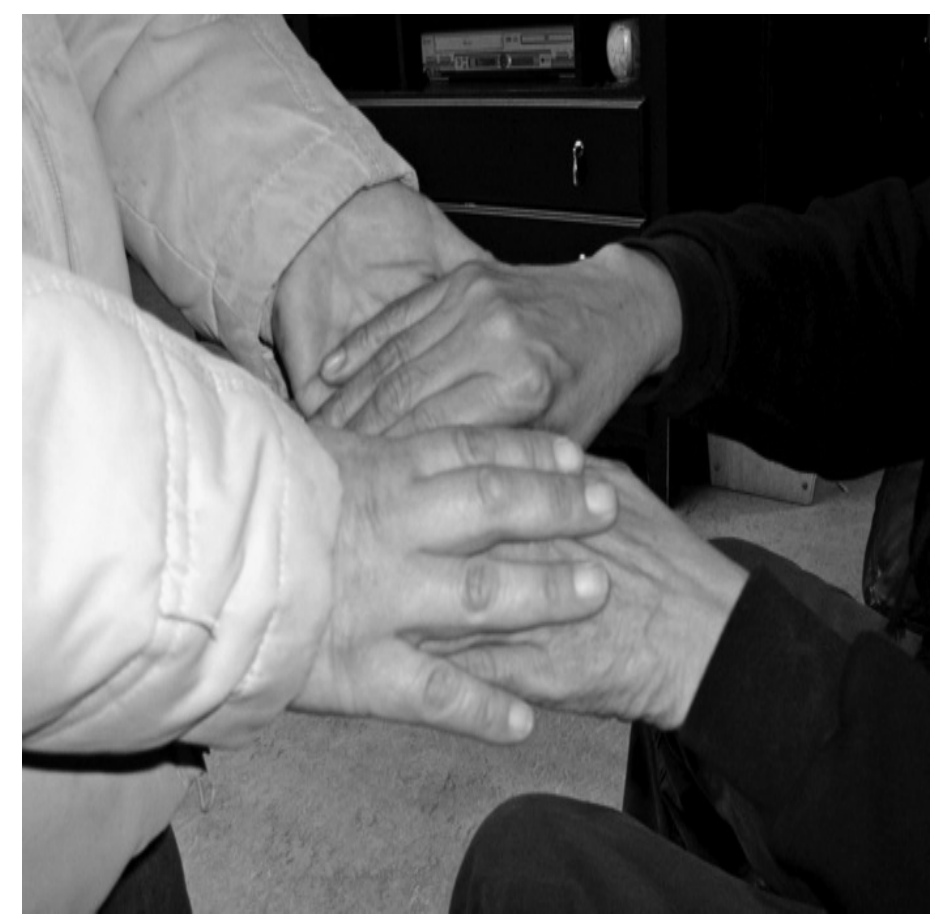

Figure 5

The Clock. The clock represents all the time that I lost through my alcoholism - time - I want to get back on the right track and the right time again so I can realize what I'm doing. To me time means lots of things.

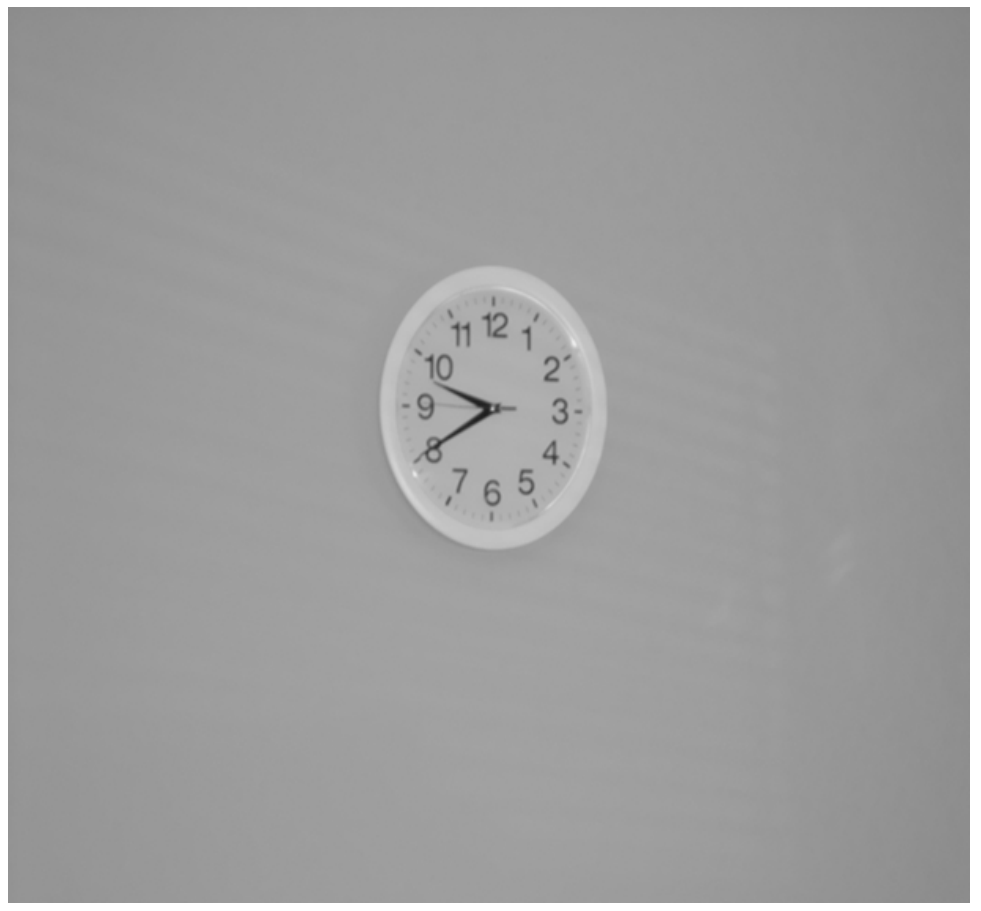

The woman who contributed this image has since passed away due to health problems. Her participation in the project appeared to be reflective of healing and a offered a moving representation of the concept of time. 


\section{Discussion of Figures}

These images and text provide a brief glimpse into the depth and richness of the experiences of this project's participants. Many of the women, upon reviewing their images, spoke at length about varied experiences involving relationships with family members, support and lack of support in their lives, alcoholism, health problems, and being homeless. Each woman engaged in long dialogues while reviewing photographs and creating captions, and this work offers a window into their lives. For example, the image and text provided in Figure 5 shared the concept of time and meaning, around issues of alcoholism and moving forward, in this particular woman's life. Many rich discussions occurred as team members engaged with participants in preparing their final product in Photovoice. What did we learn that was important about conducting research in the North?

\section{Key Principles in Research on FASD Prevention in the Northwest Territories, Canada}

The following principles have been identified as critical for research on the topic of FASD prevention in the NT:

- The foundations of health and healing are critical constructs in FASD prevention.

- Engaging in FASD prevention work in the North requires a culturally sensitive approach.

- FASD is a sensitive topic, and when talking about it in the North, it needs to be carefully approached and related to other health-based initiatives in communities.
- Connections with communities are forged over time, through visits and presence.

- Photovoice is an engaging methodology for working with women on health issues.

- The experience of homeless women is profoundly different from other communities. These women spoke more frequently about troubles with addiction and loss of children to care.

In order to offer a stronger insight into the project, Table 1 gives descriptions of the images provided by three woman participants, with their captions and accompanying text. (Space limitations do not permit the inclusion of all the participants' work. Therefore, while it must be understood that the key constructs identified above were generated from a combined analysis of all the participants in this community.) These woman's voice represents struggle and resilience. Women talked about their experiences and the challenges they faced, being homeless in Yellowknife. Initially, one woman stated that she would join the project and that she could "sell that camera." The researcher simply responded, "Could you wait a couple of days?" This woman became truly engaged in the project and while we do not know if she later sold the camera, she returned with 27 photos, and we had lengthy discussions about many issues in her life that provided insight into her perspectives on health and healing. A pervasive sense that women appreciated being able to talk about their experiences through their photographs was present in the work done in this project.

Table 1

Brightening Our Home Fires: Coding and quotations related to addiction, alcohol, intervention and homelessness from a woman experiencing homelessness and living in a center in the Northwest Territories

\begin{tabular}{|c|c|}
\hline $\begin{array}{l}\text { Image } \\
\text { Description }\end{array}$ & Participant Quotations \\
\hline $\begin{array}{l}\text { Downtown } \\
\text { Yellowknife }\end{array}$ & $\begin{array}{l}\text { Caption: I keep trying and trying } \\
\text { I try to keep away from drinking. Sometimes people ask me and it's an excuse to go out. Sometimes I can't help it. } \\
\text { This is the cop station. We drink in this parking lot, hide and drink in a circle. We get money for alcohol mostly } \\
\text { through recycling and panhandling, mostly panhandling. The alley is where we usually drink. I just keep healthy. I just } \\
\text { keep myself busy, staying in, staying away from downtown, keeps busy. I start to drink downtown - meet up with } \\
\text { people. If I don't want to drink I just walk away. I come and go. }\end{array}$ \\
\hline $\begin{array}{l}\text { Kitchen table, } \\
\text { chairs and } \\
\text { computer }\end{array}$ & $\begin{array}{l}\text { Caption: Working on this project } \\
\text { This is the first thing I'm starting on just trying to learn one day at a time, working on those things like learning } \\
\text { computers instead of being out there and enjoying myself in this life. Doing simple things to keep my mind away from } \\
\text { other things I have done in my life. If I just stay forward hopefully there is something out there that will keep my mind } \\
\text { off drinking and find a simple thing to keep me doing other things I want to do in my life. May the good spirit always } \\
\text { be with us. }\end{array}$ \\
\hline $\begin{array}{l}\text { A chair in the } \\
\text { centre in } \\
\text { Yellowknife }\end{array}$ & $\begin{array}{l}\text { Caption: I need sober friends } \\
\text { I've been drinking since my younger days and I started at age 13. Okay, and I was drinking heavy on and off, and I } \\
\text { was doing good in school. I was doing good in school and I started hanging out with different kinds of friends. That's } \\
\text { where everything went wrong - back to drinking, smoking, sniffing gas, glue. I'd drink anything I could lay my } \\
\text { hands on, just to drink with friends, family so I can be in the crowd, be one of them. And sometimes we stay up all } \\
\text { night and we don't sleep, lack of sleep. Sometimes we don't eat. I was always sick on and off on all the garbage. . .It } \\
\text { really hurts to be. . .homeless, sleepless, no food, I was killing myself. . somehow I really have to slow down. I'm not } \\
\text { getting any younger. I need to stay with sober friends, talk about my feelings. I hope if someone listens to me, they } \\
\text { think twice about this. I'm getting older. I'm not getting any younger, so if anybody understands about these problems, } \\
\text { please listen and try to give help. It's hard to do it on your own. Think twice before you get any older. Talk to } \\
\text { someone, ask for help. }\end{array}$ \\
\hline
\end{tabular}




\begin{tabular}{lc}
\hline $\begin{array}{l}\text { Image } \\
\text { Description }\end{array}$ & Participant Quotations \\
\hline $\begin{array}{l}\text { Magazine } \\
\text { Advertisement - } \\
\text { Two out of three }\end{array}$ & $\begin{array}{c}\text { Caption: It's hard out there } \\
\text { Well sometimes when they fall back and they're not trying hard enough to come back up and give up on themselves - } \\
\text { they stay where they are - they stay on the street. I was abused. I was drinking days in and days out. I wasn't eating } \\
\text { getting enough - } \\
\begin{array}{l}\text { gtatistics Canada, } \\
2004\end{array}\end{array} \quad \begin{array}{l}\text { good. I wasn't sleeping good. I never thought about nothing, about returning to what I used to be. After a few days, I } \\
\text { in that circle where I used to be, but now I slow down and hopefully I'll get through struggling about this life. We're } \\
\text { just going back and forth. If I tried thinking harder, maybe I'll get where I want to be. }\end{array}$ \\
\hline
\end{tabular}

\section{Discussion}

The BOHF Project in Yellowknife, NT offered a new way to understand the experience of homeless women living in a centre. Circulating an invitation to participate led to the recruitment of eight women participants, each of whom shared her viewpoints on the meaning of health and healing in their community. Using Photovoice as a methodological approach provided a great deal of information and helped to ascertain knowledge about the lived experience of women in the North.

Why is this research important? It is important because it provides women with an opportunity to give voice to their experiences in relation to health, and to inform us from a deeply personal position, through the pictures they took and their reflections on the meanings these images hold. The $\mathrm{BOHF}$ research also provided a venue for women to engage and learn new skills, such as using a digital camera, and to have conversations about health in their lives. The process of working with the women, once they returned with pictures, allowed for deep engagement and dialogue on a one-to-one basis. We believe that the images taken by these women portray powerful information about their lives. This approach supports a woman-first perspective and focuses the lens on health and healing as viewed by the photographer/project participant. Reflections through images and words focused on relationships - with the land, with family members and within the community and highlighted experiences that were both positive and negative. The use of the camera as a tool to express ideas of health and healing was an enlightening experience for participants and the research team.

\section{Conclusion}

The Brightening Our Home Fires project, while ultimately about FASD prevention, offered wide-ranging insight into health and healing concerns for women in the North. The images and text generated by this project contained a depth of knowledge regarding broader social issues in this region, such as poverty, homelessness, health-related services, lack of employment opportunities, education, recovery from past trauma, addiction, housing and personal safety. It is not possible within the context of this article to address all these concerns; yet identifying them brings a level of awareness that is grounded in the experience and voice of women in the North.
While discussion of FASD prevention took place at the outset of this work through two processes - the initial presentation and invitation to participate, and the signing of informed consents - it was clear that the broader construct of health informed much of this research. A range of perspectives was offered through Photovoice, and viewpoints emerged that reflected connection and disconnections, the meaning of life that is rooted in tradition, culture and connection to the land. In some cases, another side of life emerged, particularly for struggling, disenfranchised homeless women in Yellowknife. Providing cameras to women engaged in this project, and asking about health and healing perspectives in their lives, has contributed to the development of knowledge about their experiences. Many women found joy and a sense of accomplishment in taking photographs, and shared that, through a camera lens, they saw aspects of their lives in new ways. Photovoice presents an excellent avenue for exploration of complex health topics with women.

This work was predicated on the understanding that FASD prevention is best achieved through research that is relevant and informed by women through a deeper understanding of their lived experience. Subsequently, knowledge dissemination and sharing the value of Photovoice, image and text-based research can lead to different ways of thinking about social issues and problems such as FASD prevention in women's lives.

\section{Acknowledgments}

The authors acknowledge the Centre for Northern Families, and its past executive director Arlene Hache. We also acknowledge the women participants who shared their time and engaged in this research project. We also acknowledge the methodological consultant, Dr. Christine Walsh from the University of Calgary, who provided initial Photovoice training in Yellowknife in 2011. We also acknowledge the support of the Aurora Research Institute and Dr. Pertice Moffitt of Yellowknife, NT, for her guidance and direction. We want to thank and acknowledge all individuals we encountered in the NT who were interested in and supportive of this project. We also acknowledge the support of Nancy Poole from the B.C. Centre of Excellence in Women's Health and lead of the Network Action Team (NAT) on Women's Social Determinants of Health with The Canada FASD Research Network, and the other team members, including Dr. Amy Salmon, Sandra Lockhart and 
Marilyn Van Bibber, who all supported and worked on this project. We would also like to thank research assistant Jamie Hickey, for her support in completing this manuscript.

\section{References}

Badry, D. E. (2012). Brightening our home fires final report. (Unpublished report). First Nations Inuit Health Branch, University of Calgary, Calgary, AB, Canada.

Briggs, C., \& Pepperell, J. (2009). Women, girls, and addiction: Celebrating the feminine in counseling treatment and recovery. New York, NY, United States: Routledge, Taylor \& Francis Group.

Doyle, M., \& Timonen, V. (2010). Lessons from a community-based participatory research project: Older people's and researchers' reflections. Research in Aging, 32, 244-263.

Hunting, G., \& Browne, A. (2012). Decolonizing policy discourse: Reframing the "problem" of fetal alcohol spectrum disorder. Women's Health and Urban Life, $11,35-53$.

Lavallee, J., \& Poole, J. (2009). Beyond recovery: Colonization, health and healing for Indigenous people in Canada. International Journal of Mental Health and Addictions, 8, 271-281.

Moffitt, P. (2012). Telling it like it is "anyways”: Capturing Tlicho pregnancy experiences through Photovoice. Pimatisiwin: A Journal of Aboriginal and Indigenous Community Health, 10, 207-216.

Palibroda, B., Krieg, B., Murdock, L., \& Havelock, J. (2009). A practical guide to Photovoice: Sharing pictures, telling stories and changing communities. Winnipeg, MB, Canada: The Prairie Women's Health Centre of Excellence.

Poole, N. (2007). Gender does matter: Coalescing on women and substance use. CrossCurrents: The Journal of Addiction and Mental Health, 10, 8.

Poole, N., \& Greaves, L. (Eds.). (2007). Highs and lows: Canadian perspectives on women and substance use. Toronto, ON, Canada: Centre for Addiction and Mental Health.

Rutman, D., Callahan, M, Lundquist, A, Jackson, S,, \& Field, B. (2000). Substance use and pregnancy: Conceiving women in the policy-making process. Ottawa, ON, Canada: Status of Women in Canada.

Salmon, A., Browne, A. J., \& Pederson, A. (2010) "Now we call it research": Participatory health research involving marginalized women who use drugs. Nursing Inquiry, 17, 336-345.

Salmon, A., \& Clarren, S. K. (2011). Developing effective, culturally appropriate avenues to FASD diagnosis and prevention in Northern Canada. International Journal of Circumpolar Health, 70, 428-433.

Woodley-Baker, R. (2009). Private and public experience captured: Young women capture their everyday lives and dreams through photo-narratives. Visual Studies, 24, 19-35. 